\title{
Long-term outcomes in primary spinal osteochondroma: a multicenter study of 27 patients
}

\author{
Daniel M. Sciubba, MD, ${ }^{1}$ Mohamed Macki, BS, ${ }^{1}$ Mohamad Bydon, MD, ${ }^{1}$ \\ Niccole M. Germscheid, MSc, ${ }^{2}$ Jean-Paul Wolinsky, MD, ${ }^{1}$ Stefano Boriani, MD, ${ }^{3}$ \\ Chetan Bettegowda, MD, PhD, ${ }^{1}$ Dean Chou, MD, ${ }^{4}$ Alessandro Luzzati, MD, ${ }^{5}$ \\ Jeremy J. Reynolds, MBChB, FRCS, ${ }^{6}$ Zsolt Szövérfi, MD, ${ }^{7}$ Patti Zadnik, MD, ${ }^{1}$ \\ Laurence D. Rhines, MD, ${ }^{8}$ Ziya L. Gokaslan, MD, ${ }^{1}$ Charles G. Fisher, MD, MHSc, FRCSC, ${ }^{9}$ \\ and Peter Paul Varga, MD ${ }^{7}$
}

'Department of Neurosurgery, Johns Hopkins University School of Medicine, Baltimore, Maryland; 'Research Department, AOSpine International, Davos, Switzerland; '3Department of Degenerative and Oncological Spine Surgery, Rizzoli Institute, Bologna, Italy; ${ }^{4}$ Department of Neurological Surgery, University of California, San Francisco, California; ${ }^{5}$ Oncologia Ortopedica e Ricostruttiva del Rachide, Istituto Ortopedico Galeazzi, Milano, Italy; ${ }^{\circ}$ Spinal Division, Oxford University Hospital NHS Trust, Oxford, United Kingdom; ${ }^{7}$ National Center for Spinal Disorders and Buda Health Center, Budapest, Hungary; ${ }^{8}$ Department of Neurosurgery, MD Anderson Cancer Center, The University of Texas, Houston, Texas; and 'Division of Spine, Department of Orthopaedics, University of British Columbia and Vancouver Coastal Health, Vancouver, BC, Canada

OBJECT Clinical outcomes in patients with primary spinal osteochondromas are limited to small series and sporadic case reports. The authors present data on the first long-term investigation of spinal osteochondroma cases.

METHODS An international, multicenter ambispective study on primary spinal osteochondroma was performed. Patients were included if they were diagnosed with an osteochondroma of the spine and received surgical treatment between October 1996 and June 2012 with at least 1 follow-up. Perioperative prognostic variables, including patient age, tumor size, spinal level, and resection, were analyzed in reference to long-term local recurrence and survival. Tumor resections were compared using Enneking appropriate $(E A)$ or Enneking inappropriate surgical margins.

RESULTS Osteochondromas were diagnosed in 27 patients at an average age of 37 years. Twenty-two lesions were found in the mobile spine (cervical, thoracic, or lumbar) and 5 in the fixed spine (sacrum). Twenty-three cases (88\%) were benign tumors (Enneking tumor Stages 1-3), whereas $3(12 \%)$ exhibited malignant changes (Enneking tumor Stages IA-IIB). Sixteen patients (62\%) underwent en bloc treatment-that is, wide or marginal resection-and $10(38 \%)$ underwent intralesional resection. Twenty-four operations (92\%) followed EA margins. No one received adjuvant therapy. Two patients (8\%) experienced recurrences: one in the fixed spine and one in the mobile spine. Both recurrences occurred in latent Stage 1 tumors following en bloc resection. No osteochondroma-related deaths were observed.

CONCLUSIONS In the present study, most patients underwent en bloc resection and were treated as EA cases. Both recurrences occurred in the Stage 1 tumor cohort. Therefore, although benign in character, osteochondromas still require careful management and thorough follow-up.

http://thejns.org/doi/abs/10.3171/2014.10.SPINE14501

KEY WORDS neoplasm; osteochondroma; spine; tumor; oncology

\begin{abstract}
ABBREVIATIONS EA = Enneking appropriate; $\mathrm{EC}=$ Enneking classification; EI = Enneking inappropriate; $\mathrm{HME}=$ hereditary multiple osteochondroma/exostosis . SUBMITTED May 19, 2014. ACCEPTED October 16, 2014.

INCLUDE WHEN CITING Published online March 20, 2015; DOI: 10.3171/2014.10.SPINE14501.

DISCLOSURES This study received financial support from AOSpine International through the AOSpine Knowledge Forum Tumor, a pathology-focused working group acting on behalf of AOSpine International. Study support was provided directly through AOSpine's Research department and AO's Clinical Investigation and Documentation unit. The authors report no conflict of interest concerning the materials or methods used in this study or the findings specified in this paper. Dr. Gokaslan is the recipient of research grants from DePuy Spine, AOSpine North America, Medtronic, NREF, Integra Life Sciences, and K2M; he receives fellowship support from AOSpine North America; and he holds stock in Spinal Kinetics and US Spine. Dr. Chou is a consultant for Medtronic, Globus, DePuy, and Orthofix. Dr. Rhines is a consultant for Stryker and Globus. Dr. Sciubba is the recipient of a research grant from DePuy Spine and he has consulting relationships with Medtronic, NuVasive, Globus, Stryker, and DePuy. Dr. Fisher is a consultant for Medtronic and NuVasive; has received a grant from OREF; and has received fellowship support from AOSpine and Medtronic. Dr. Reynolds has received support from DePuy Synthes and Globus for non-study-related clinical or research effort.
\end{abstract}


$\mathrm{O}$ STEOCHONDROMA, or osteocartilaginous exostosis, is the most common benign tumor of the long bones, ${ }^{27}$ accounting for $40 \%$ of all benign bone tumors. ${ }^{18}$ The lesion appears in either single and sporadic form or multiple and hereditary form, known as hereditary multiple exostoses (autosomal dominant). ${ }^{27}$ Rarely do osteochondromas affect the vertebral column; however, approximately $3 \%$ of solitary and $7 \%-9 \%$ of hereditary osteochondromas are found in the spine. ${ }^{27}$

Spinal osteochondromas compose only $0.4 \%$ of all intraspinal tumors, and their unique characteristics are poorly understood. ${ }^{16}$ Some argue that osteochondromas are not true neoplasms but rather hamartomas herniating from the epiphyseal growth cartilage before children reach skeletal maturity.,213,23,29 These lesions are not usually identified until adulthood, with a mean age of 39 years at diagnosis. ${ }^{26}$ Given that these exophytic growths arise from the posterior elements of the spine, osteochondromas are commonly managed with posterior resection.

A paucity of evidence is available to guide the treatment of osteochondromas of the spine. Because of their low incidence, generating sufficient clinical data has been challenging. To date, most treatment regimens and reported outcomes have been based on anecdotal surgeon experience appearing as case reports and small case series. ${ }^{14,26,27,29}$ The aim of this study was to report long-term clinical outcomes from an international collection of 27 patients with spinal osteochondroma who had received surgical treatment between October 1996 and June 2012 and to determine the prognostic variables associated with local recurrence and survival.

\section{Methods}

An international, multicenter ambispective study on primary osteochondroma of the spine was performed with the support of AOSpine International through the AOSpine Knowledge Forum Tumor, a pathology-focused working group acting on behalf of AOSpine International. Spine centers from around the world that demonstrated sufficient primary tumor patient volumes (at least 10 patients per year) with a good research track record were identified. This included 9 centers from 5 countries within North America and Europe. Institutional review board or ethics committee approval was obtained by each center.

\section{Data Collection}

A secure, web-based application to support data capture (REDCap [Research Electronic Data Capture], Vanderbilt University) was used where the AOSpine Knowledge Forum Tumor developed 7 custom modules, which included demographic, clinical, diagnostic, therapeutic, local recurrence, cross-sectional survival, and perioperative morbidity information. Data were gathered both prospectively and retrospectively from patient clinical charts and institutional databases; that is, information on osteochondroma cases was collected from both previous institutional cases and new case presentations. When mortality (including cause) information was unknown, governmental vital statistics databases were accessed. A study coordinator was employed to assist with data collection, data entry, and capture of cross-sectional survival data. Patients were included if they were diagnosed with an osteochondroma of the spine and received surgical treatment between October 1996 and June 2012 with at least 1 follow-up.

\section{Definitions}

Location of the osteochondroma was characterized by its site of origin in either the mobile (cervical, thoracic, or lumbar) or the fixed (sacrum) spine. Tissue involvement by the tumor was considered anterior, posterior, both, and complete, according to the 12 zones proposed by the Weinstein, Boriani, Biagnini (WBB) surgical staging system. ${ }^{3}$ Anterior involvement includes only anterior elements (Zones 4-9): vertebral body and/or pedicles. Posterior involvement includes only posterior elements (Zones 1-3, Zones 10-12): lamina, transverse process, spinous process, transverse process, and/or articular facet joints. Tumor involvement of "both" categories includes tumor invasion of both anterior and posterior elements, and "complete" tumor involvement invades all 12 zones.

\section{Resection Methods}

Surgical treatment was categorized based on the surgeon's assessment of the resection method: intralesional versus en bloc (wide or marginal). Intralesional resection involves piecemeal dissection or curettage without achieving wide excisional margins ${ }^{15}$ En bloc resection requires a wide or marginal excision that typically involves total vertebrectomy or spondylectomy. On the other hand, wide en bloc resections include a margin of normal tissue around the tumor, whereas marginal en bloc resections refer to an incision along the tumor pseudocapsule. ${ }^{5}$ For osteochondroma, the goal of en bloc excision is to resect the entire cartilaginous cap. Often en bloc excisions involve a vertebrectomy or spondylectomy. However, en bloc resection in osteochondromas that involve the posterior elements may be amenable to removal of the spinous process and lamina. Radical resections, which would entail resection of the entire anatomical compartment, are not clinically feasible in the spinal column.

\section{Enneking Principles}

The Enneking classification (EC) is a tumor staging system that reflects the interrelationship of biological grade, tumor extension, and metastasis.$^{8,9}$ Ranging from Stage 1 to Stage IIIB, the tumor classification scheme is intended to guide resection. ${ }^{10}$ Curettage (intralesional) gross-total resection is acceptable for benign lesions such as Stage 1 (latent) and Stage 2 (active) tumors. For Stage 3 tumors, en bloc marginal excisions are recommended. For more aggressive tumors (Stages IA-IIB), en bloc resection with wide margins is the surgical goal. Additionally, in high-grade malignancies, adjuvant treatment is critical. Finally, metastases (Stages IIIA-IIIB) are managed with palliative treatment. ${ }^{5}$ Cases treated with the recommended resection are Enneking appropriate (EA), while those that are not treated according to the recommended resection are Enneking inappropriate (EI).

\section{Statistical Analysis}

Descriptive statistics (means \pm standard deviations or 
frequency and percentages) were generated. All statistical analyses were performed using Stata (version 12.0, StataCorp). Statistical significance was set at $\mathrm{p} \leq 0.05$.

\section{Results}

\section{Patient and Tumor Characteristics}

Osteochondroma of the spine was diagnosed in 27 patients: 16 males and 11 females with a mean age of $37 \pm$ 18 years. Details on patient demographics, tumor characteristics, surgical treatment, recurrence, and survival are presented in Tables 1 and 2.

Osteochondromas were more frequently located in the mobile spine (22 patients [81\%]), whereas only 5 patients (19\%) presented with a tumor in the fixed spine. Over 50\% of cases were limited to 1 vertebral level, whereas $11 \%$ (3 cases) encompassed 4 or more vertebrae. Of the 20 cases reporting tissue involvement, most tumors invaded all or a portion of the posterior spinal elements (16 cases; Table 2). Twenty-six cases reported a mean tumor size of $3.23 \pm$ $2.29,2.73 \pm 1.95$, and $2.57 \pm 2.02 \mathrm{~cm}^{3}$ in the anteroposterior, left-right, and cranial-caudal dimensions, respectively. Tumor size was not reported for 1 patient. Most of the benign tumors were classified as latent Stage 1 (16 cases
[70\%]), and malignant transformations were also observed ( 3 cases [12\%]; Table 3). Pain was reported in 20 patients (74\%), and on clinical presentation, 4 patients (15\%) exhibited signs and symptoms of myelopathy.

\section{Tumor Resection and Enneking Appropriateness}

The EC was known for 26 cases and correlated with the pathologist's postoperative impressions on whether the surgery was EA or EI. All tumors were surgically managed: 10 patients (38\%) underwent intralesional resection and $16(62 \%)$ underwent en bloc resection (wide or marginal). The surgical margins were unknown in 1 patient. A posterior approach was performed in 20 patients (77\%), an anterior approach in 5 patients (19\%), and a combined approach in 1 patient (4\%). Surgical approach was not reported in 1 patient. None of the patients received adjuvant therapy.

The Enneking appropriateness was not available for 1 patient. Of the 26 cases analyzed using the Enneking principles, 24 (92\%) were classified as EA. Intralesional resections were applied to a Stage IB and IIA osteochondroma; therefore, these operations were EI. The follow-up period for EA cases ranged from 3 days to 15.4 years (median 11

TABLE 1. Summary of tumor and treatment factors in 27 patients with spinal osteochondroma

\begin{tabular}{|c|c|c|c|c|c|c|}
\hline Case No. & Age at Op (yrs) & Tumor Level & Tumor Vol $\left(\mathrm{cm}^{3}\right)$ & Tumor Stage* & Resection Type & Local Recurrence \\
\hline 1 & $35, F$ & C-7 & 16 & 1 & En bloc & \\
\hline 2 & $48, M$ & S-1 & 4 & 1 & En bloc & Yes \\
\hline 3 & $46, M$ & C-7 & 3 & 2 & Intralesional & \\
\hline 4 & $46, F$ & T9-10 & 2 & 1 & Intralesional & \\
\hline 5 & $61, \mathrm{M}$ & $\mathrm{L}-2$ & 2 & 1 & Intralesional & \\
\hline 6 & $65, M$ & C3-T2 & 4 & 1 & En bloc & \\
\hline 7 & $48, M$ & S-1 & 120 & 1 & En bloc & \\
\hline 8 & $43, F$ & C6-7 & 2 & 1 & En bloc & \\
\hline 9 & $76, F$ & T11-12 & 4 & 2 & Intralesional & \\
\hline 10 & $21, \mathrm{M}$ & S-1 & 120 & 2 & En bloc & \\
\hline 11 & $49, F$ & C5-7 & 1 & 1 & Intralesional & \\
\hline 12 & $17, \mathrm{M}$ & S-1 & 27 & 1 & En bloc & \\
\hline 13 & $32, \mathrm{M}$ & L4-5 & 1 & 1 & Intralesional & \\
\hline 14 & $60, M$ & T-12 & 8 & IIA & Intralesional & \\
\hline 15 & $68, F$ & $\mathrm{~L}-2$ & 4 & 2 & Intralesional & \\
\hline 16 & $13, F$ & $\mathrm{~T}-1$ & 6 & 1 & En bloc & \\
\hline 17 & $19, \mathrm{M}$ & $L-5$ & 24 & 1 & En bloc & \\
\hline 18 & $38, \mathrm{M}$ & L4-5 & 6 & 1 & En bloc & \\
\hline 19 & $20, M$ & $L-5$ & 4 & 1 & En bloc & \\
\hline 20 & $36, F$ & T11-12 & 150 & 1 & En bloc & Yes \\
\hline 21 & $26, \mathrm{M}$ & C4-5 & 4 & 1 & Intralesional & \\
\hline 22 & $33, F$ & L-1 & 152 & 3 & En bloc & \\
\hline 23 & $21, M$ & $\mathrm{~T}-7$ & 36 & IB & En bloc & \\
\hline 24 & $28, M$ & T1-2 & Unknown & Unknown & Unknown & \\
\hline 25 & $13, \mathrm{M}$ & L5-S3 & 616 & 2 & En bloc & \\
\hline 26 & $17, \mathrm{~F}$ & C1-3 & 7 & IB & Intralesional & \\
\hline 27 & $22, \mathrm{~F}$ & T8-11 & 336 & 2 & En bloc & \\
\hline
\end{tabular}

En bloc $=$ wide or marginal.

* 1 = benign inactive; 2 = benign active; 3 = benign aggressive; $I \mathrm{~B}=$ malignant low grade; $I \mathrm{~A}=$ malignant high grade . 
TABLE 2. Summary of demographic and outcome data for 27 patients with spinal osteochondroma

\begin{tabular}{|c|c|}
\hline Variable & No. $(\%)$ \\
\hline Mean age at diagnosis in yrs & $37 \pm 18$ \\
\hline \multicolumn{2}{|l|}{$\operatorname{Sex}(n=27)$} \\
\hline Male & $16(59)$ \\
\hline Female & $11(41)$ \\
\hline \multicolumn{2}{|l|}{ Mobile spine location $(n=22)^{*}$} \\
\hline Cervical & $7(32)$ \\
\hline Thoracic & $9(41)$ \\
\hline Lumbar & $7(32)$ \\
\hline \multicolumn{2}{|l|}{ Tissue involvement $(n=20)$} \\
\hline Anterior & $4(20)$ \\
\hline Posterior & $8(40)$ \\
\hline Both & $7(35)$ \\
\hline Complete & $1(5)$ \\
\hline \multicolumn{2}{|l|}{ Resection $(n=26)$} \\
\hline Intralesional & $10(38)$ \\
\hline En bloc & $16(62)$ \\
\hline \multicolumn{2}{|l|}{ Local recurrence $(n=27)$} \\
\hline No & $25(93)$ \\
\hline Yes & $2(7)$ \\
\hline \multicolumn{2}{|l|}{ Survival status ( $\mathrm{n}=27$ ) } \\
\hline Dead & $4(15)$ \\
\hline Alive & $23(85)$ \\
\hline
\end{tabular}

months), whereas the follow-up in EI cases ranged from 2.4 to 4.9 years (median 3.7 years).

\section{First Local Recurrence}

A first local recurrence was reported in 2 patients (8\%) within 5 years postoperatively: at 1.5 years in a patient with an osteochondroma in the fixed spine and at 4.6 years in a patient with an osteochondroma in the mobile spine. Both recurrences occurred in cases of latent Stage 1 tumors. In terms of surgical treatment, both recurrences occurred in patients managed with en bloc resections that were EA. All postoperative patients were routinely screened with serial radiographic images to monitor tumor recurrence.

\section{Survival}

Overall, 4 patients $(15 \%)$ died within 2.4 years postoperatively; all causes were unrelated to the spinal osteochondroma. None of the patients who died reported a local recurrence. Patients were followed up for a mean of $2.7 \pm 4$ years (range 3 days to 15.4 years, median 1.5 years).

\section{Discussion}

We present the first and largest multicenter clinical study reporting local recurrence and survival outcomes in patients with diagnosed primary spinal osteochondroma. We found that the thoracic spine had the greatest number of tumor cases and that the sacral spine had the lowest
TABLE 3. Spinal osteochondromas stratified according to the Enneking classification

\begin{tabular}{cc}
\hline Variable & No. (\%) \\
\hline Enneking classification & $23(88)$ \\
\hline Benign & $3(12)$ \\
\hline Malignant & \\
\hline Stage, benign cases & $16(70)$ \\
\hline Latent Stage 1 & $6(26)$ \\
\hline Active Stage 2 & $1(4)$ \\
\hline Aggressive Stage 3 & \\
\hline Stage, malignant cases & $3(100)$ \\
\hline Stage IA-IIB & $0(0)$ \\
\hline Other &
\end{tabular}

number. These results differ from previous findings in which $50 \%$ of osteochondromas appeared in the cervical spine, ${ }^{1}$ with the most commonly affected level at C-2, followed by $\mathrm{C}-3$ and C-6;,27 the thoracic spine has been reported to be the second most commonly affected region, most often at the T- 8 level, followed by T-4. ${ }^{18,26,27}$ We attribute these discrepancies to the larger surface area of the thoracic versus the cervical spine.

Osteochondromas are thought to arise from the excessive cartilaginous tissue of secondary ossification centers in the posterior elements of the spine, ${ }^{25}$ namely the tip of the spinous or transverse process. ${ }^{26}$ Commensurate with this hypothesis, $60 \%$ of tumors in the present study had some type of posterior element involvement. Although some authors have speculated that the cellular cycle in the ossification centers is faster in the upper vertebrae,${ }^{11}$ others have postulated that repeated microtrauma of the mobile cervical spine probably displaces the epiphyseal growth cartilage, which in turn develops into hamartomas. ${ }^{1,18} \mathrm{An}$ other risk factor contributing to the formation of osteochondromas includes radiation exposure to the epiphyseal growth zone. ${ }^{7}$ Approximately $12 \%-15 \%$ of these tumors arise secondary to the administration of more than $25 \mathrm{~Gy}$ of radiation in children younger than 2 years of age. ${ }^{26}$

In agreement with data in other studies, osteochondroma in the present study was more frequently diagnosed in males. ${ }^{4,6,24-26,30}$ Given that osteochondromas arise from the tip of the posterior spinal elements, the outward growths are rarely symptomatic. ${ }^{21,26}$ The most common presenting symptom is nonmechanical spinal pain, or biological (tumor-related) pain. When tumor does invade the spinal canal, compressive myelopathy and sciatica are the most common presentations. ${ }^{11,18,25,26}$ In the present series, $74 \%$ of patients reported pain, whereas $15 \%$ exhibited signs and symptoms of myelopathy. Signs and symptoms of spinal cord injury may not be apparent on taking a history and performing a physical examination; therefore, spinal tumors require a high index of clinical suspicion and thorough clinical examination before subjecting patients to imaging studies.

On gross surgical pathology, osteochondroma appears as a pediculated or sessile growth of hyaline cartilage centrally and perichondrium peripherally that is continuous with the periosteum of the underlying bone. ${ }^{19}$ Radiograph- 
ically, osteochondromas have a stalk and body composed of mature bone, covered by a cartilaginous cap that does not ossify and is therefore unidentifiable on radiographs. The tumor characteristically exhibits a cortical margin continuous with surrounding bone. Computed tomography is helpful in determining the osseous origins of the tumor (Fig. 1A and C).${ }^{14}$ On MRI, the cartilaginous cap is iso- to hyperintense on T1-weighted sequences and hyperintense on T2-weighted sequences (Fig. 1B and D). ${ }^{27}$ Although the nonvascular cartilage does not enhance with Gd contrast, the tumor may exhibit peripheral enhancement due to the fibrovascular tissue overlying the cartilaginous cap. ${ }^{12}$ Malignant changes should be suspected when the cartilaginous cap is thicker than $3 \mathrm{~cm}$, when patients report the new onset of symptoms, or when the tumor rapidly increases in size. ${ }^{27}$

The rate of malignant transformation for osteochondroma is less than $1 \%$ in solitary cases and approximately $3 \%-5 \%$ in hereditary cases. ${ }^{17}$ These figures are based on studies in the appendicular skeleton; unfortunately, the rate of malignancy has not been well established in the axial skeleton. In the present series, the rate of malignant transformation was slightly higher at $11 \%$ (3 cases). This rate may reflect an intrinsically higher incidence of malignancy in the spine or a selection bias given the tertiary referral centers included in the study. None of the participating centers reported a history of hereditary osteochondromas in affected patients.

Although Stage 1 and 2 tumors are amenable to intralesional resections per the Enneking principles, en bloc resections were performed in 14 patients $(52 \%)$ with benign lesions because of the technical feasibility of the operation and/or the surgeon's comfort with and/or preference for en bloc resections. Nevertheless, the risk of postoperative recurrence for solitary osteochondromas after excision is low, ranging from $2 \%$ to $5 \%$ in limited case reports and case series without adequate follow-up. ${ }^{18,20,29}$ Here, we report a slightly higher overall recurrence incidence of $8 \%$ ( 2 cases). Both recurrences were treated with wide or marginal resections. While these findings may be counterintuitive, these recurrences may reflect a failure to obtain marginal or wide margins after presumed gross-total resection. A failure to resect the cartilaginous tumor cap (unbeknownst to the surgeon) may also cause recurrences. Moreover, the en bloc cohort represented a disproportionately larger number of patients (16 patients [62\%]). In addition, the en bloc resection cohort was followed up for a mean of 3.2 years (range 4 days-15.4 years, median 1.6 years), which was longer than for the cohort overall. Therefore, recurrence rates may reflect an uneven distribution of patients with a follow-up bias. Similarly, although both recurrences happened in patients who underwent EA resections, the EA cohort (24 patients) represented the largest percentage of patients who were also followed up for the longest period of time. Again, the higher recurrence rate in the EA group may reflect the uneven distribution of patients in the EA cohort versus the EI cohort. In the EI cohort, 2 patients with Stage IB and IIA tumors were managed with intralesional resections. These 2 cases were treated with intralesional resections probably because of an unanticipated high-grade tumor diagnosis on surgical
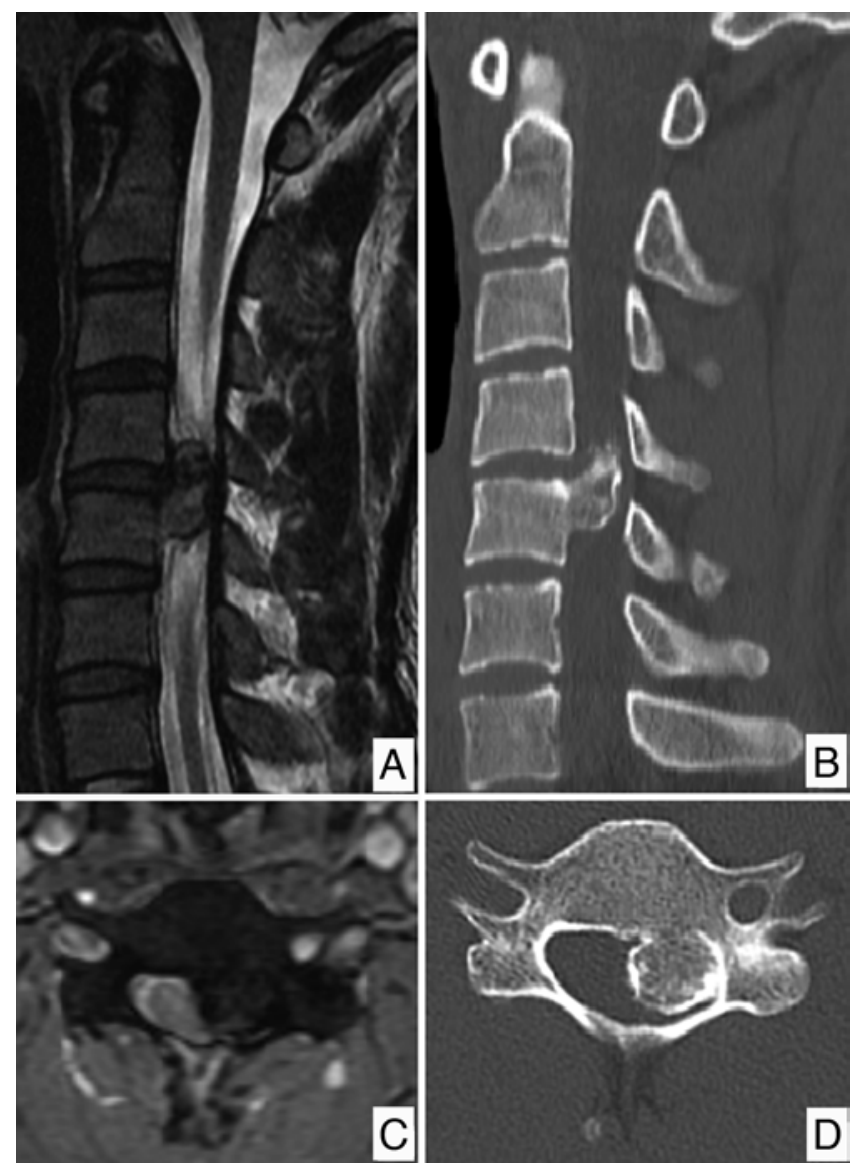

FIG. 1. A 25-year-old man presented with a 4-month history of neck pain and left arm paresthesias. Preoperative CT (A and C) suggested an osteochondroma arising from the superior aspect of the C-5 vertebral body on the left with mild superior extension into the left aspect of the spinal canal. Preoperative MRI (B and D) revealed a sessile lesion arising from the dorsal and superior aspect of the $\mathrm{C}-5$ vertebral body on the left with rightward displacement of the spinal cord.

pathology. However, recurrences were not observed in these 2 patients.

We also observed that both recurrences appeared in patients with Stage 1 benign tumors. Morton contends that the reappearance of osteochondroma may not reflect a true recurrence. ${ }^{22} \mathrm{~A}$ recurrence would imply an aggressive character of the osteocartilaginous tumor cap, which is consistently removed during tumor resection. Instead, the reappearance of osteochondroma may represent a new primary lesion adjacent to the initial tumor site. Although multiplicative growth of osteochondromas has been wellestablished in hereditary multiple osteochondroma/exostosis (HME) syndrome, ${ }^{31}$ new research suggests that solitary osteochondroma and HME are a spectrum of diseases from the same family of tumor suppressor genes denoted EXT. Thus, even with solitary lesions, new tumors may arise in juxtaposition to the index lesion without the full onset of HME.

Given the characteristics of patients with recurrences in the present study, we infer that although osteochondromas are dormant lesions, the tumors still require careful surgical management. In a working diagnosis of osteochondroma, en bloc resections with EA margins are preferred 
because the pathological diagnosis of a benign-appearing lesion may return with malignant features. Moreover, even with benign lesions, osteochondroma can still recur at an incidence of $8 \%$, as observed in the present study. Thus, proper follow-up with serial imaging is essential. Similar findings have been reported in the literature..$^{5,10,28,29}$ In a study of primary spinal bone tumors, Talac et al. reported a local recurrence rate of $55.6 \%$ in patients with positive margins; however, recurrences persisted at an incidence of $16.7 \%$ with negative margins. ${ }^{28}$ Of those patients with negative margins, the incidence of recurrence decreased to $11.1 \%$ with an en bloc resection and increased to $33 \%$ with an intralesional resection. According to the literature, these same principles apply to Enneking appropriateness. Although Fisher et al. reported a statistically higher recurrence rate following EI resection, the incidence of recurrence was still $20 \%$ following EA resection..$^{10}$

Osteochondromas are characteristically associated with a favorable prognosis. Overall, none of the deaths in the present study were attributable to the osteochondroma. Because benign lesions are considered hamartomas rather than true neoplastic lesions, the disease-specific mortality is considered negligible. These findings are starkly different from those on other primary spinal bone tumors in which mortality is directly attributable to tumor recurrence. $^{10}$

\section{Study Limitations}

While we report the largest multicenter analysis of ambispectively collected clinical data on the long-term first local recurrence and survival of patients with osteochondroma of the spine, this study remains limited because of the small sample size, the small number of events, and the unevenly distributed data. For rare diseases, obtaining enough data for scientific evaluation is challenging. Note that a central review of the neoplastic pathology could not be performed in the present study. In addition, most patients were censored within 5 years postoperatively. Performing detailed prospective studies would broaden our understanding of the osteochondroma disease course.

\section{Conclusions}

We present the first and largest multicenter clinical study on primary spinal osteochondroma. After evaluating the 15-year surgical outcomes of 27 patients with spinal osteochondromas, we found that no deaths were attributable to the tumor. The incidence of local recurrence was $8 \%$ (2 patients). Most patients underwent en bloc resection and were treated as EA, and both recurrences had these 2 features. The recurrences appeared in cases of Stage 1 tumors. Thus, although they are benign lesions, osteochondromas still require careful surgical management and thorough follow-up.

\section{Acknowledgments}

We are grateful to the collaborating centers' local clinical research personnel and support staff for their active participation. This study was organized by AOSpine International through the AOSpine Knowledge Forum Tumor, a pathology-focused working group of up to 10 international spine experts acting on behalf of AOSpine in the domain of scientific expertise. AOSpine is a clinical division of the AO Foundation - an independent medically guided not-for-profit organization dedicated to improving patient care worldwide.

\section{References}

1. Albrecht S, Crutchfield JS, SeGall GK: On spinal osteochondromas. J Neurosurg 77:247-252, 1992

2. Arasil E, Erdem A, Yüceer N: Osteochondroma of the upper cervical spine. A case report. Spine (Phila Pa 1976) 21:516518, 1996

3. Boriani S, Weinstein JN, Biagini R: Primary bone tumors of the spine. Terminology and surgical staging. Spine (Phila Pa 1976) 22:1036-1044, 1997

4. Calhoun JM, Chadduck WM, Smith JL: Single cervical exostosis. Report of a case and review of the literature. Surg Neurol 37:26-29, 1992

5. Chan P, Boriani S, Fourney DR, Biagini R, Dekutoski MB, Fehlings MG, et al: An assessment of the reliability of the Enneking and Weinstein-Boriani-Biagini classifications for staging of primary spinal tumors by the Spine Oncology Study Group. Spine (Phila Pa 1976) 34:384-391, 2009

6. Cooke RS, Cumming WJ, Cowie RA: Osteochondroma of the cervical spine: case report and review of the literature. $\mathbf{B r}$ J Neurosurg 8:359-363, 1994

7. Cree AK, Hadlow AT, Taylor TK, Chapman GK: Radiationinduced osteochondroma in the lumbar spine. Spine (Phila Pa 1976) 19:376-379, 1994

8. Enneking WF: A system of staging musculoskeletal neoplasms. Clin Orthop Relat Res (204):9-24, 1986

9. Enneking WF, Spanier SS, Goodman MA: A system for the surgical staging of musculoskeletal sarcoma. Clin Orthop Relat Res (153):106-120, 1980

10. Fisher CG, Saravanja DD, Dvorak MF, Rampersaud YR, Clarkson PW, Hurlbert J, et al: Surgical management of primary bone tumors of the spine: validation of an approach to enhance cure and reduce local recurrence. Spine (Phila Pa 1976) 36:830-836, 2011

11. Fiumara E, Scarabino T, Guglielmi G, Bisceglia M, D'Angelo V: Osteochondroma of the L-5 vertebra: a rare cause of sciatic pain. Case report. J Neurosurg 91 (2 Suppl):219-222, 1999

12. Geirnaerdt MJ, Bloem JL, Eulderink F, Hogendoorn PC, Taminiau AH: Cartilaginous tumors: correlation of gadoliniumenhanced MR imaging and histopathologic findings. Radiology 186:813-817, 1993

13. Gille O, Pointillart V, Vital JM: Course of spinal solitary osteochondromas. Spine (Phila Pa 1976) 30:E13-E19, 2005

14. Govender S, Parbhoo AH: Osteochondroma with compression of the spinal cord. A report of two cases. J Bone Joint Surg Br 81:667-669, 1999

15. Ibrahim A, Crockard A, Antonietti P, Boriani S, Bünger C, Gasbarrini A, et al: Does spinal surgery improve the quality of life for those with extradural (spinal) osseous metastases? An international multicenter prospective observational study of 223 patients. J Neurosurg Spine 8:271-278, 2008

16. Jayakumar P, Indira Devi B, Shenoy SN, Santosh V, Shankar SK: Thoracic spinal osteochondroma causing cord compression: a report of five cases. Indian J Radiol Imaging 8:117120,1998

17. Karasick D, Schweitzer ME, Eschelman DJ: Symptomatic osteochondromas: imaging features. AJR Am J Roentgenol 168:1507-1512, 1997

18. Khosla A, Martin DS, Awwad EE: The solitary intraspinal vertebral osteochondroma. An unusual cause of compressive myelopathy: features and literature review. Spine (Phila Pa 1976) 24:77-81, 1999

19. Kitsoulis P, Galani V, Stefanaki K, Paraskevas G, Karatzias 
G, Agnantis NJ, et al: Osteochondromas: review of the clinical, radiological and pathological features. In Vivo 22:633646, 2008

20. Moon KS, Lee JK, Kim YS, Kwak HJ, Joo SP, Kim IY, et al: Osteochondroma of the cervical spine extending multiple segments with cord compression. Pediatr Neurosurg 42:304-307, 2006

21. Moriwaka F, Hozen H, Nakane K, Sasaki H, Tashiro K, Abe H: Myelopathy due to osteochondroma: MR and CT studies. J Comput Assist Tomogr 14:128-130, 1990

22. Morton KS: On the question of recurrence of osteochondroma. J Bone Joint Surg Br 46:723-725, 1964

23. Nielsen OG, Gadegaard L, Fogh A: Osteochondroma of the cervical spine. J Laryngol Otol 100:733-736, 1986

24. Ratliff J, Voorhies R: Osteochondroma of the C5 lamina with cord compression: case report and review of the literature. Spine (Phila Pa 1976) 25:1293-1295, 2000

25. Sakai D, Mochida J, Toh E, Nomura T: Spinal osteochondromas in middle-aged to elderly patients. Spine (Phila Pa 1976) 27:E503-E506, 2002

26. Sharma MC, Arora R, Deol PS, Mahapatra AK, Mehta VS, Sarkar C: Osteochondroma of the spine: an enigmatic tumor of the spinal cord. A series of 10 cases. J Neurosurg Sci 46:66-70, 2002

27. Srikantha U, Bhagavatula ID, Satyanarayana S, Somanna S, Chandramouli BA: Spinal osteochondroma: spectrum of a rare disease. J Neurosurg Spine 8:561-566, 2008

28. Talac R, Yaszemski MJ, Currier BL, Fuchs B, Dekutoski MB, Kim CW, et al: Relationship between surgical margins and local recurrence in sarcomas of the spine. Clin Orthop Relat Res (397):127-132, 2002

29. Tubbs RS, Maddox GE, Grabb PA, Oakes WJ, Cohen-Gadol
AA: Cervical osteochondroma with postoperative recurrence: case report and review of the literature. Childs Nerv Syst 26:101-104, 2010

30. Tully RJ, Pickens J, Oro J, Levine C: Hereditary multiple exostoses and cervical cord compression: CT and MR studies. J Comput Assist Tomogr 13:330-333, 1989

31. Wuyts W, Schmale GA, Chansky HA, Raskind WH: Hereditary multiple osteochondromas. GeneReviews. (http://www. ncbi.nlm.nih.gov/books/NBK1235/) [Accessed February 2, 2015]

\section{Author Contributions}

Conception and design: Sciubba, Gokaslan. Acquisition of data: Sciubba, Germscheid, Boriani, Bettegowda, Reynolds, Szövérfi, Zadnik, Rhines, Fisher, Varga. Analysis and interpretation of data: Sciubba, Germscheid, Bettegowda, Reynolds, Zadnik, Gokaslan, Fisher, Varga. Drafting the article: Sciubba, Macki, Bydon, Reynolds, Fisher. Critically revising the article: Sciubba, Macki, Bydon, Germscheid, Reynolds. Reviewed submitted version of manuscript: Sciubba, Macki, Bydon, Fisher, Germscheid, Bettegowda, Chou, Luzzati, Reynolds, Gokaslan, Fisher, Varga. Approved the final version of the manuscript on behalf of all authors: Sciubba. Statistical analysis: Germscheid. Administrative/technical/material support: Sciubba, Germscheid, Wolinsky, Boriani, Reynolds, Zadnik, Gokaslan, Fisher, Varga. Study supervision: Sciubba, Wolinsky, Boriani, Gokaslan, Fisher, Varga.

\section{Correspondence}

Daniel M. Sciubba, Department of Neurosurgery, The Johns Hopkins Hospital, Meyer 7-113, 600 N. Wolfe St., Baltimore, MD 21287. email: dsciubb1@jhmi.edu. 